\title{
Public Policy and Youth Employment: An Empirical Study of Cameroon's Experience
}

\author{
Désiré AVOM ${ }^{1}$, Bernard NGUEKENG ${ }^{1}$ \& Iréné TIAKO ${ }^{2}$ \\ ${ }^{1}$ Searcher in "Laboratoire d'Analyse et de Recherche en Economie Appliquée (LAREA)“, University of \\ Yaoundé II Soa, Cameroon \\ ${ }^{2}$ Searcher in Laboratory of Analysis and Research in Mathematical Economics (LAREM), University of Yaoundé \\ II, Cameroon \\ Correspondence: Iréné TIAKO, University of Yaoundé II, Cameroon.
}

Received: May 6, 2021

doi:10.5539/ibr.v14n7p69

\author{
Accepted: June 4, 2021 \\ Online Published: June 22, 2021 \\ URL: https://doi.org/10.5539/ibr.v14n7p69
}

\begin{abstract}
The aim purpose of this paper is to assess the contribution of public policies on youth employment in Cameroon. To do this, we used the multinomial Logit model that is being followed up for our employment equation. The maximum probability method is the estimation technique used and applied to data extracted from the EISS database (2011). Three main results emerge from this study: (1) young people who wish to self-employment do not have adequate training and the technical and financial support offered to them by the government is insufficient; (2) the incentives proposed by the State to private operator to encourage them to recruit young people do not always contribute to this objective and (3) the massive recruitments carried out by the State fail to pay off all unemployed young people. In this situation, the Cameroonian state should further strengthen the professionalization of training and, above all, guide training offers in the areas that present opportunities in our country. It also needs to strengthen the facilities afforded to private companies to encourage them to recruit more young people. We also suggest that the Cameroonian government provide more technical and material support to young people who are seeking it and, on the other hand, to raise more funds for the bankable projects presented by these Last.
\end{abstract}

Keywords: interlocking multinomial Logit model, maximum probability method, public policies, youth employment

\section{JEL Classification: H52, H53, J18; J23, C35, C51}

\section{Introduction}

At the end of January 2014, at the initiative of the International Development Research Centre (IDRC) and Thinks Tank, an international conference was held on the issue of youth employment in Sub-Saharan Africa. It brought together development partners, national and regional decision-makers. Indeed, statistics produced by specialized institutions show that the issue of youth employment spares no regardless of its level of development. For example, and for example, in France, the youth unemployment rate reached 24\% in 2017. In Sub-Saharan Africa, it is higher and varies, according to the AfDB in 2016, between $30 \%$ and $40 \%$.

The situation in Cameroon follows this general trend as young people find it difficult to access decent employment. Unemployment and underemployment of young people are reaching very high levels. According to the results of the Employment and Informal Sector Survey (EISS 2011), about 23.8\% of young people aged 17 to 35 are unemployed, especially in urban areas (46\%). According to the ILO, overall underemployment is about $89 \%$. Rural youth are the most affected, with about $94 \%$ under-employed compared to $85 \%$ of urban youth, with an increased number of highly skilled youth. However, this last tranche is the major major target.

In response, the Government of Cameroon undertook several actions, including the creation in 1990 of the National Employment Fund (NEF), whose role is to promote employment by facilitating the meeting between offers and applications. In December 2004, a ministerial department was created and entirely dedicated to employment and vocational training. In order to ensure transparency in the labour market and transform the informal sector, the National Observatory for Employment and Vocational Training (NOEVT) was set up and the Integrated Support Project for Actors in the Informal Sector (ISPAIS) was implemented. In all regions of the 
country, experimental projects for disadvantaged young people are operational, such as the Youth and Associative Life for Social Insertion (YALSI) programme. In order to integrate young people, MINJEC has implemented the Rural and Urban Youth Support Programme (RUYSP) and the Youth Socio-Economic Integration Project through the creation of micro-enterprises for the Manufacture of Sports Materials (PIFMAS).

Aware of the place of young people in the total population (36.28\%), the dynamism of this age group (17-35 years) and its ability to match current technological developments, the Government of Cameroon has undertaken these various actions with the aim of significantly reducing the unemployment of these young people and ensuring the socio-economic development of Cameroon. But despite all these different actions, the expected results are below expectations. Thus, the government's concern about the evaluation of these policies is legitimate. As a result, several questions emerge: what are the main challenges faced by young job seekers? Do the various actions defined by the Government take these difficulties into account? Are these actions accessible to all young people? Which of these actions is most favourable to the employment of cameroonian youth?

In view of the above and in the light of the literature that points out that public action interventions for youth employment concern coaching, financial support, labour taxation, the minimum wage and the performance of the training system (World Bank, 2012; Nicoletti \& Scarpetta, 2005; Nunziata, 2002; Nickell, 1997), this study aims to ascertain whether all the measures initiated by the Cameroonian Government promote youth employment. Specifically, we are talking about assessing the effects of these measures on access to employment or not on the one hand and on the type of employment on the other. The originality of this study is based on the methodology adopted. It is based on the use of an embonomial multinomial logit model that has the advantage of taking into account both levels of evaluation.

After this introduction, which is the subject of the first section, the rest of the article is organized in the following way. The second section is devoted to a brief review of literature. The third presents the characteristics of the labour market and the various public policies in favour of youth employment in Cameroon. Methodology, data and estimation techniques are presented in the fourth section. The fifth section presents and analyzes the results. The sixth concludes and suggests some economic policy recommendations.

\section{Public Policy and the Labour Market: A Selective Review of Literature}

Faced with the persistence of problems of access to employment for young people, economists of all theoretical currents have tried to revise their interpretations. The neoclassicals have proposed new explanations of unemployment, either in terms of dysfunction as in the standard theory, or in terms of the rationality of the unemployed. Keynesians continued to explain unemployment by insufficient demand. Since the 1990s, in the search for key measures to facilitate access to employment in general and access to employment for young people in particular, the role of public policy has increasingly been considered in analyses. Our readings show that these public actions in the labour market have three main orientations. The first group of programmes focuses on the demand side of the labour market and the second on the supply side, while the third group aims to improve the functioning of the labour market.

On the applicant side, governments have attempted to encourage recruitment by reducing the cost to employers of providing employment (Crépon \& al., 2012). The analysis of a reduction in the cost of labour centred on a particular category (for example, young workers) leads to the distinction of three main mechanisms. The impact on employment may first result from a micro-economic substitution effect, the extent of which depends on the elasticity of substitution between the different factors of production (youth work, the work of experienced people and capital). Also at the micro-economic level, the lowering of the cost of a factor has a mechanical impact on the cost of production of the company. The latter can pass this decrease on to its selling price, and thus see the demand addressed to it increase. At the same time, price adjustments can lead to substitution effects at the macro level, passing through the relative prices of different products according to their relative intensity in different factors of production: for example, a fall in the cost of youth labour should lead to an increase in the relative demand for goods and services whose production is intensive in young work (and thus, symmetrically, a decline in the relative demand for capital intensive goods and services of experienced people). However, in order to fully appreciate the overall impact of such a measure on employment (not only low-skilled), it would also be necessary, beyond the effects we have just mentioned, to take into account the effects of macroeconomic "closure", and in particular those related to the financing arrangements of the measure.

Empirical studies show that the issue of the relationship between labour costs and youth employment was far from unanimous in the economist community. The debate focused in particular on the effects of the minimum wage. In the United States, the decline in the federal minimum wage (in relative and real terms) during the 1980s, and its sharp increase between 1989 and 1991, had not had a significant impact on employment (Card \& Krueger, 
1997).

In addition to the minimum wage, other studies have considered the reduction of social security contributions. Whether it is work based on forward-looking assessments (Laroque \& Salanié, 1999), computable general equilibrium models, estimated microsimulation models based on wage and participation equations (Laroque \& Salanié, 1999) or retrospective evaluations (Crépon \& al., 2012), the results are those of a significant positive effect of the reduction of social contributions on total employment.

For labour offerers, public policy involves several actions (Ryan, 2001). First, education policy measures are based on the idea that youth unemployment is due to a problem of inadequate or inadequate training. The main objective of these schemes is to bring education systems closer together in order to improve the adaptation of skills to the needs of the productive apparatus. This group includes alternating training contracts: apprenticeship contract, adaptation contract and qualification contract (Sabina Issehnane, 2009; Nickell, 1997). Research has suggested that higher levels of education and cognitive skills are associated with economic growth (Hanushek \& Woessmann, 2012) and the employment of a larger share of young people in the modern non-agricultural wage sector (Lee \& Newhouse, 2012). If increased educational attainment is not associated with a greater accumulation of skills, schooling will have a limited effect on overall growth and the composition of employment.

Second, governments can intervene directly in the labour market by creating non-market jobs and facilitating the conditions of creation, particularly in the field of new technologies. Indeed, the development of new technologies has increased the dependence of the countries of the South, as they have been created and patented in developed countries. Moreover, it is essentially the multinational companies that hold the rights. In recent decades, the demand for new technologies has gained new dynamism and contributed to the creation of new jobs. However, many of these jobs are in developed countries, although they now tend to be more evenly distributed as a result of the increasing internationalization of production processes controlled by large companies. New technologies generally lead to labour savings. This should not lead us to refuse them, but rather to seek to put in place an active policy of ownership and development of their applications, exploiting the progress that often manifests itself at the national level.

Finally, assisted merchant contracts are part of deregulation policies. The political economy model of unemployment argues that radical labour market reform is needed to combat structural unemployment. Some studies conclude that the level of unemployment compensation and its duration have a significant impact on unemployment (Scarpetta, 1996; Nickell, 1998). Similarly, a number of empirical studies find that heavy taxation of labour tends to increase the unemployment rate (Bassanini \& Duval, 2009; Nickell, 1997), although other studies are less conclusive in this regard (Scarpetta, 1996; Elmeskov \& al., 1998; Nunziata, 2002). In addition, some macro-term studies identify a favourable effect on overall labour market expenditure (MTPA) spending on active labour market policies and an adverse effect of homeownership, but they do not agree on the extent of these effects (Scarpetta, 1996; Green \& Hendershott, 2001, Nickell \& al., 2005).

Regarding measures to improve the functioning of the labour market, (Nickell, 1997) confirms in a study examining the effects of institutions on fluctuations in the employment rate on several countries in Europe that the factors influencing mainly the duration of unemployment benefits, unionization rates, coordination between employers and employees, taxation on labour, the minimum wage and the performance of the training system. Similarly, the World Bank states that labour market regulation provides important social protections for workers in terms of: employment contracts, severance pay, unemployment benefits, dismissal grounds, trade union rights, or the scope of collective bargaining.

\section{Some Stylized Facts about the Labour Market in Cameroon}

Two main concerns are ours in this section. The first relates to the socio-professional situation of young people in Cameroon. The second refers to the variety of actions initiated by the Cameroonian Government on behalf of these young people.

\subsection{A Labour Market Dominated by High Youth Unemployment}

The labour force participation rate is one of the indicators that allows us to assess the dynamics in the labour market. Its fluctuations give an indication of the market's ability to open up or close to job creation. In addition to this indicator, we also have the unemployment that characterizes the labour market in Cameroon.

\subsubsection{High Unemployment among Cameroonian Youth}

According to the results of the Employment and Informal Sector Survey (EISS, 2011), about 23.8\% of young people aged 17 to 35 are unemployed. This rate hides disparities by gender, age, region of residence and degree. 
By gender, women are more affected (26.3\%) men (19.6\%). Comparing these rates with those of overall unemployment (18.8\% for women and $11.6 \%$ for men) there is a greater discouragement among women in finding a job. At the regional level, in addition to the major metropolises, notably Douala and Yaounde with about $40.4 \%$, young people from the Adamaoua and South-West regions are the most affected by unemployment with rates above the national average. It should also be noted that the phenomenon is more pronounced in urban areas where the average rate is $27.4 \%$ compared to $14.3 \%$ in rural areas. The rise in educational attainment does not appear to be a parade against unemployment. The unemployment rate is generally higher among those with the higher level. Indeed, it is $13.7 \%$ among those holders of the BAC/GCEAL/BEP, $22.8 \%$ for those with BTS/DUT/DEUG/NHD, $15.7 \%$ for licensees/BD and 10.4\% for master's/DEA/Master/MBA holders.

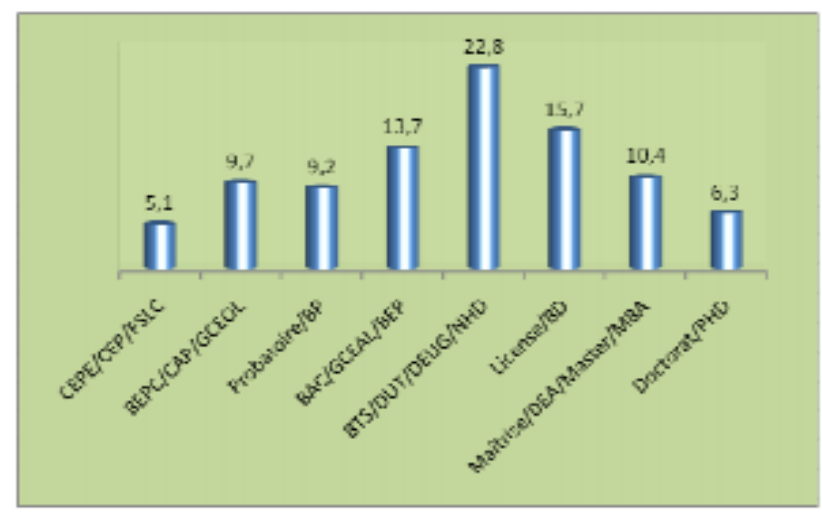

Figure 1. ILO unemployment rate according to the highest degree (\%)

Source: EISS 2 database (INS, 2011)

The majority of these unemployed are first-time job seekers. In fact, they are 59.5\% first-time applicants compared to $40.5 \%$ for those who have already held a job. Moreover, unemployment is long-term, with $56.4 \%$ of them looking for work for more than a year, with an average duration of unemployment of 34.3 months. This is higher in rural areas (46.2 months) than in urban areas (31.2 months).

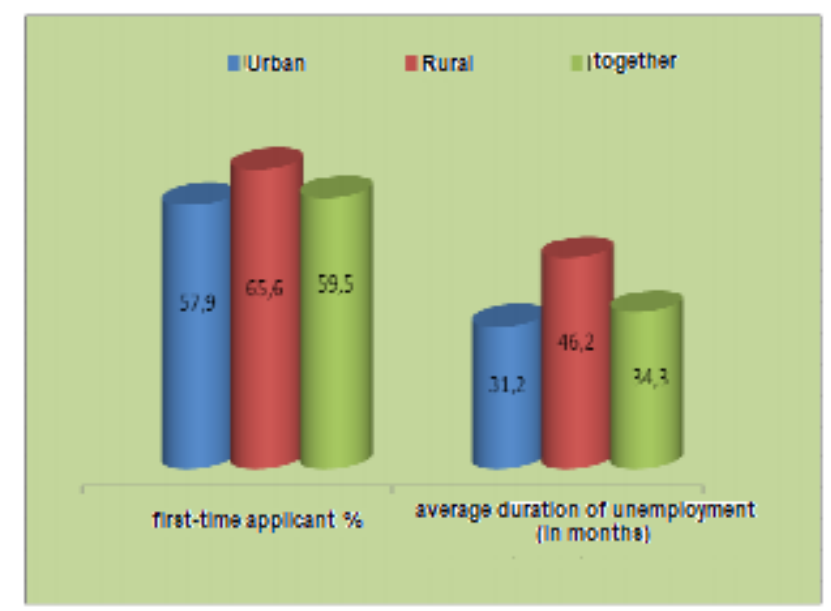

Figure 2. Characteristics of the unemployed

Source: EISS 2 database (INS, 2011)

\subsubsection{Preference of These Unemployed for Formal and Well-Paid Employment (This Is the Public Offer)}

The majority of unemployed people, for job security reasons, have a preference for employment in the public or formal private sectors. Among the unemployed, $65.9 \%$ prefer to be employed in the public or formal private 
sector, $21.6 \%$ are in self-employment and $12.4 \%$ are indifferent. Compared to the level of education, almost 8 out of 10 unemployed at the higher level prefer a salaried job, compared to those at the secondary level, who are $26.2 \%$ in favour of self-employment. It is therefore not out of the question that some, already active in the informal sector, are candidates for public policy.

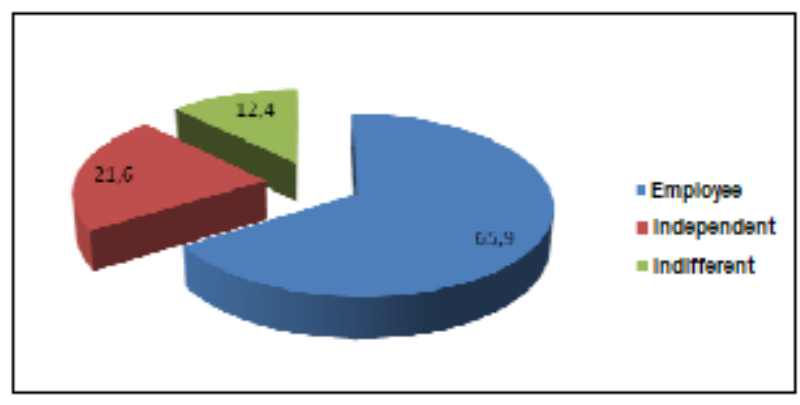

Figure 3. Jobs sought by graduates aged 17 to $40(\%)$

Source: EISS2 database (INS, 2011)

For young Cameroonians in the [17-35] age group with at least one degree, the average wage claims are 119,412 CFA francs per month, 156,323 CFA francs per month for men and 99,484 CFA francs for women. These wage claims grow with the diploma. In fact, they go from about 70,728 CFA francs for those with the CEP or a diploma equivalent to 400,000 CFA francs among those with a Doctorate to 201,416 CFA francs for those with a BTS or equivalent degree. On the other hand, regardless of the degree, men have consistently higher wage claims than women.

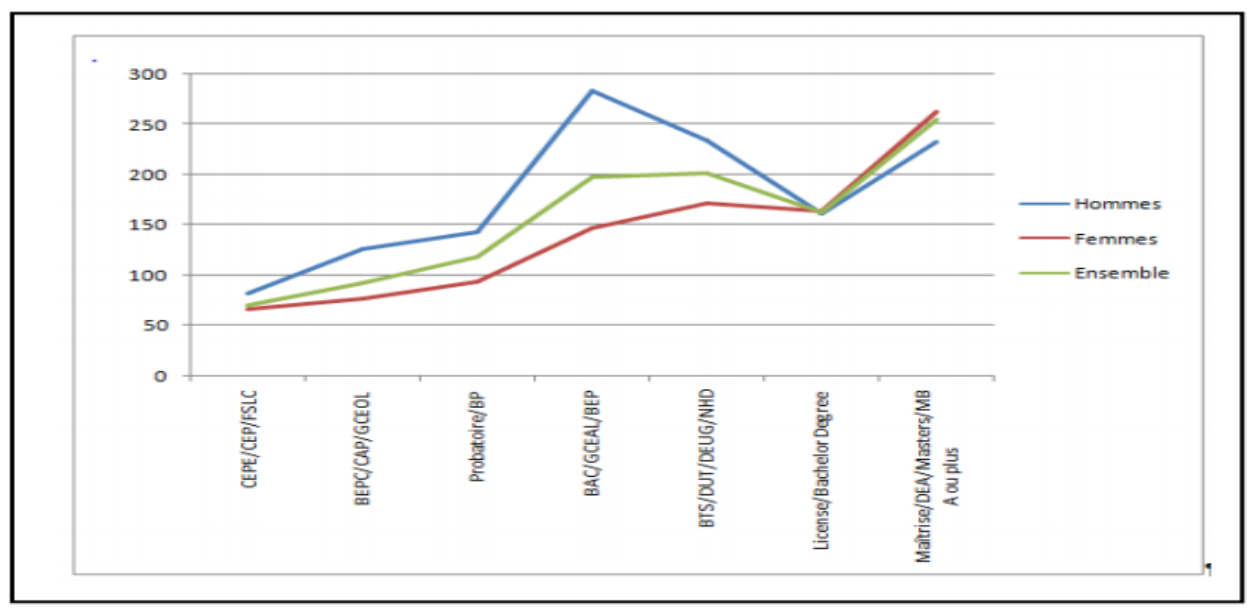

Figure 4. Wage claims among those in school aged 17 to 35 , in thousands of FCFA, by gender

Source: EISS2 database (INS, 2011)

\subsection{Public Policies for Youth Employment}

Economic theory points out that public policies in favour of employment can be grouped into two main categories: active and passive policies. This second group of measures is to make unemployment bearable by the unemployed by guaranteeing them an income and to reduce the unoccupied labour force. These include unemployment insurance, the compensation of the unemployed, which aims to provide some income security for people who are not employed. Unable to implement these measures, the Government of Cameroon has opted for active policies aimed at improving young people's access to paid employment and encouraging their autonomy. The first group of programmes focuses on the demand side of the labour market and the second on the supply side, while the third group aims to improve the functioning of the labour market. 


\subsubsection{Cameroonian State Actions on Behalf of Labour Force Actors}

Knowing that the demand for work in the Cameroonian labour market is the work of public and private actors, we present here the measures taken by the government to boost it.

- Measures for private demand

The Cameroonian government has taken a number of actions to remove barriers to private sector development and business creation, and to enable the private sector to act as a driving force for growth and economic development. These actions focus on the liberalisation and simplification of administrative procedures and taxation. The Cameroonian government has also undertaken, with the help of external partners, to provide the SME landscape with new support instruments more in line with the new liberal economic orientations. Specific actions are also being taken towards SMEs and are coordinated within the Priority Sme Promotion Programme (PSPP). This programme aims, among other things, to promote the private sector through the creation and development of SMEs, to create jobs and to strengthen the capacity of women, young people and people with disabilities to start businesses.

The new investment code provides incentives for businesses to create new jobs. Thus, the SME scheme is granted to companies that create at least one permanent job for Cameroonians increments of less than or equal to five (5) million CFA francs of investments planned by the company and of which at least $35 \%$ of the capital is held by Cameroonians or Cameroonian legal entities. These measures, which enable the development of private enterprises, will ultimately encourage the recruitment of young people into private companies. We have the case of companies working in different sectors of activity that recruit young people, notably the Breweries of Cameroon, Orange Cameroon, MTN, to name but a few.

- Measures for public demand

These measures include the recruitment in 2011 of 25,000 public officials between the ages of 17 and 40 in the Public Service. This decision, which is very far-reaching politically and socio-economically, has been welcomed by all populations. They see it as a beginning to solve the thorny problem of unemployment, especially that of young graduates, some of whom have been desperate for employment for more than a decade; Direct recruitment competitions in the various public administrations open to young people aged 17 to 35; the development of the partnership with the socio-professional circles provided by the Ministry of Higher Education; Advocacy for youth employment and internships in public and private services provided by the Ministry of Youth and Civic Education; Etc.

\subsubsection{The Actions of the Cameroonian State in Favour of the Actors of the Labour Offer}

Knowing that competence is the key to employment, the Cameroonian government has invested in both university and vocational training for young people. While vocational training is a long-standing concern of the Cameroonian government, its regulation and diversification were strengthened by Law 76/12 of 08 July 1976 . These texts officially create initial and continuing vocational training. This legislation, which was deemed outdated, has adjusted to the new socio-economic context. A new policy on orientation and vocational training is being developed to address a number of issues, including measures to support adjustment, ways and means to reform and optimise the infrastructure of the training system, the choice of training methods and means, the financing of vocational training, new vocational training courses to be developed., the renovation of learning, etc.

Beyond competence, the Cameroonian government has in recent years created several programmes to facilitate the self-employment of young people. The actions of these structures concern, among other things, financial, technical and material support to young people who wish to start their own business. These structures include the Rural and Urban Youth Support Programme (RUYSP); Youth Insertion Fund (YIF); National Youth Insertion Fund (NYIF); Youth Insertion Project by the creation of micro-companies for the Manufacture of Sports Equipment (PIFMAS); Integrated Informal Sector Actor Support Project (IISASP); Multi-media Development Relay Project (MDRP); Young Farmers' Settlement Support Program (YFSSP); Development of entrepreneurship and youth self-employment; Piloting and coordinating the activities of youth coaching structures; Commonwealth Youth Credit initiative; Annual Employment and Career Orientation Show; Strengthening professional integration; Socio-professional integration of girls and women (SIGW); Improved Rural Family Income (IRFI); Quantitative increase in the supply of vocational training, etc.

\subsubsection{Cameroonian State Actions to Improve the Functioning of the Labour Market}

Similarly, the definition of the policy for promoting private investment is the responsibility of MINDIC through the direction of industrial development. This directorate is also responsible for the evaluation and adaptation of 
the investment code, monitoring the activities of the National Investment Corporation (NIC), the National Office of Industrial Free Zones, industrial promotion or investment organizations, etc. The establishment of an incentive framework to attract private investment has been made effective by the Investment Code, the Free Zones Act, the Labour Code, the creation of an Investment Code Management Unit and the National Office of Free Zones and tax-customs reform.

It is clear from the above that the Cameroonian government has defined and implemented several measures in favour of youth employment. All these actions demonstrate the government's commitment to providing employment for young Cameroonians. But by looking at the number of candidates applying for these different offers, both private and public, we can safely say that young Cameroonians are quite interested. But these measures remain insufficient because not all young people who apply are always positive. As proof, direct recruitment competitions in large schools such as the 180-seat open ENAM receives nearly 6000 applications. This leads us to say that there is necessarily an imbalance between the different offers and the number of applicants. The state's limited offer is justified by the lack of means to pay these new workers. On the other hand, the low recruitment by private companies can be justified either by the lack of coincidence between the training of young people and the qualifications required, or the absence or inadequacy of the facilities granted by the State to them in order to encourage them to recruit more young people or the gloom of the economic situation which does not stimulate the employment of a large quantity of labour. Despite all these measures, it is clear that the expected results are not always achieved, as a large proportion of young Cameroonians are still unemployed. We are therefore talking about assessing the effects of these various measures taken by the government on the youth employment situation.

\section{Study Methodology}

In this section we present the interlocking multinomial logit model and the justification for its choice on the one hand, the data and variables of this model on the other.

\subsection{Introducing the Interlocking Multinomial Logit Model and Justifying Its Choice}

Historically, the study of models describing the modalities taken by one or more qualitative variables dates from the 1940s-1950s. The most striking works of this period are undoubtedly those of Berkson (1944, 1951). It was from the 1970s that these models were used to describe economic data, including the work of McFadden (1974) and Heckman (1976). Most of these used simple dichotomy models (Logit and Probit models). But when the variable to be explained has more than two modalities, dichotomous models become inappropriate, justifying the use of multinomial logistics models (Guadagni \& Little, 1983).

However, this type of model assumes proportional substitution frameworks (ownership of the independence of irrelevant alternatives, IIA), i.e. the ratio of probability choices of two alternatives $(\mathrm{Pj} / \mathrm{Pk})$ is not dependent on the presence or absence of other alternatives in the model. If the IIA test is inconclusive, an alternative model to the multinomial logit model (LM) should be used. The natural alternative to the latter is a multivariate probit model, the estimate of which is however complex in the current state of knowledge. Another more operational model has been developed to partially relax the strong IIA hypothesis; it is the interlocking multinomial logistics model (Guadagni \& Little, 1998).

This interlocking multinomial logit (LME) model is a combination of standard logit models that differs from the latter in that the components of the alternative choice error do not necessarily need the same distribution. In addition, the LME model admits, more general alternative frameworks. The idea of this model lies in a grouping of similar alternatives within subsets or subgroups, with the aim of creating a hierarchical structure of alternatives (Ben-Akiva \& Lerman, 1985; Train, 2003) which does not necessarily require that the process of individual choice be sequential. The error terms of alternatives within a (same) subset are correlated to each other, while those of alternatives in different subsets are not correlated. Thus, the IIA hypothesis is maintained within each subset, but the variance may differ between the different subsets. The interlocking multinomial logit model process thus accommodates a violation or partial loosening of IIA ownership. This model can be considered a two-tiered (or more) choice problem.

In this study, we are talking about assessing the impact of public policies on youth employment in Cameroon. However, we know that in the search for employment, young people face the difficulties that are observed at two levels. The partition of these difficulties into sub-sets or sub-groups is thus easily achievable, since one can naturally distinguish the situation of absence of employment from all other difficulties which are all employment situations. Thus, if a young person cannot find a job, then he is unemployed. On the other hand, if he gets a job, he works either as an employee of the public sector, the private sector or as a self-employed person (self-employment). This hierarchical structure of our model can be reproduced in the form of the following 
decision tree:

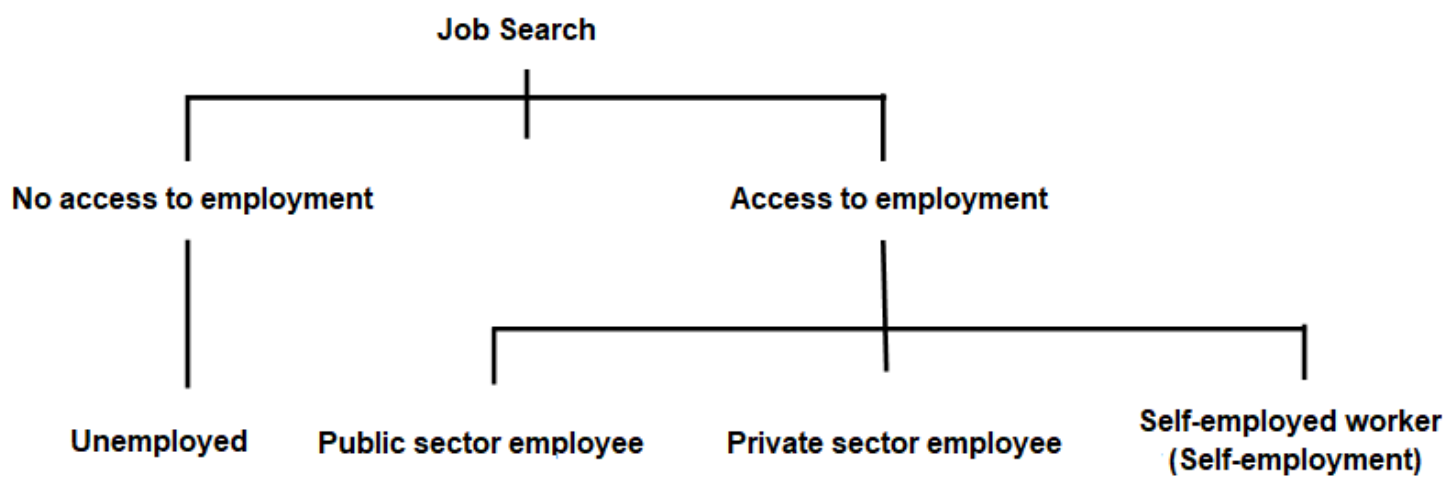

Figure 5. Multinomial logit model nestled for job search in Cameroon

Source: Authors

Let's look now at how it will be mathematically specified. Like the multinomial logit model, the mathematical specification of the nested multinomial logit model reflects the probability that a young person will be in either sector knowing that they have landed a job, and are assessed using the following equation:

$$
\operatorname{Prob}\left(Y_{i}=j / p\right)=\frac{\exp \left(\beta_{j}^{\prime} z_{i}\right)}{\sum_{k=1}^{3} \exp \left(\beta_{k}^{\prime} z_{i}\right)}
$$

The difference between the LM and LME models occurs in the process of assessing the likelihood of being unemployed rather than having access to employment. This probability becomes:

$$
\operatorname{Prob}\left(Y_{i}=0\right)=\frac{\exp \left(\beta_{0}^{\prime} z_{i 0}\right)}{\exp \left(\beta_{0}^{\prime} z_{i 0}+\exp \left(\lambda . I_{i}\right)\right)}
$$

$$
\text { With } I_{i}=\ln \left(\sum_{k=1}^{3} \exp \left(\beta_{k}^{\prime} z_{i}\right)\right)
$$

In this formulation, the zi0 vector corresponds to a set of variables specific to the explanation of access to employment or not. These may differ from the explanatory variables of obtaining employment in a sector (zi). The term Ii represents the inclusive value to the sector concerned (public, private or self-employment). In this formulation, if equal to 1, the LME model is reduced to a standard LM model. Thus, it is by allowing the term to differ from the unit that the LME model releases the IIA hypothesis through the different "branches" of the decision tree. It is maintained between choices belonging to the same subgroup, but is relaxed between subgroups. The probability of getting a job in a particular sector is written as follows:

$$
\operatorname{Prob}\left(Y_{i}=j\right)=\operatorname{Prob}\left(Y_{i}=j / p\right) *\left(1-\operatorname{Prob}\left(Y_{i}=0\right)\right)
$$

The parameters of the LME model thus defined can be estimated by the usual techniques of maximum likelihood.

It is hypothesized that residues $\varepsilon$ in the stochastic utility function have independent distributions of the type GEV (generalized extreme-value). It should also be noted that it is also possible to estimate an LME model sequentially using a step-by-step method (Maddala 1983). It is then estimated at first the ' $\mathrm{j}$ ' in the equation (1), and then the inclusive value ii is calculated. Finally, we can calculate the ' 0 ' through the equation (2). However, this method results in some loss of effectiveness in this case. However, it is very useful in evaluating large models for which the maximum likelihood method becomes difficult to use. The setting can be used to test the 
IIA hypothesis. Indeed, a test of the zero hypothesis - 1 will be an effective test of the relevance of the latter in the LM model.

\subsection{LME Data and Variables}

The data used in this work are extracted from the EISS database, i.e. the Informal Sector Employment Survey conducted in 2011 by Cameroon's National Statistical Institute (NSI). The survey base used consists of the consolidation of Cameroonian households. Renter counts the requirement of the study, individuals no age is greater than 35 years or less than 17 years were not selected in the survey database. This restriction resulted in a total population of 13110 individuals scattered throughout the national territory (see Table 5 in appendix). In order to take into account the countries of the region, the Cameroonian territory has been divided into 12 regions: Far North, North, Adamaoua, East, South, West, Southwest, Central except Yaounde, Coastal except Douala, and the cities of Douala and Yaounde are considered to be separate regions and assimilated respectively to the departments of Wouri and Mfoundi. The data used in this work are extracted from the EISS database, i.e. the Informal Sector Employment Survey conducted in 2011 by Cameroon's National Statistical Institute (NSI). The survey base used consists of the consolidation of Cameroonian households. Renter counts the requirement of the study, individuals no age is greater than 35 years or less than 17 years were not selected in the survey database. This restriction resulted in a total population of 13110 individuals scattered throughout the national territory (see Table 5 in appendix). In order to take into account the countries of the region, the Cameroonian territory has been divided into 12 regions: Far North, North, Adamaoua, East, South, West, Southwest, Central except Yaounde, Coastal except Douala, and the cities of Douala and Yaounde are considered to be separate regions and assimilated respectively to the departments of Wouri and Mfoundi. We know that one of the objectives of statistics is to observe phenomena in a homogeneous group of individuals. Thus, the exerbene Douala and Yaounde of the respective provinces Littoral and Centre will reduce the bias on the calculated indicators because these two cities are the most populated.

The multi-sector model of access to employment that we will implement is a discrete choice model. As a result, it first requires a change in the shape of the data usually used for estimating "classic" models. Indeed, the characteristics of individuals are no longer presented "on a single line", but in the form of panel data requiring each individual to write a line of characteristics for each choice available to him. This form, although more complex, has two significant advantages. On the one hand, it allows, if necessary, to choose different explanatory variables depending on the alternative that one wishes to explain. On the other hand, it allows consideration of attributes related to the different choices that the individual can make. This means that it allows different variables to be taken into account, for the same individual, depending on the choice he or she makes.

This specific form of data can be particularly interesting for the study of access to employment. Indeed, it can be considered that the different possibilities offered to each individual are not necessarily explained by the same variables. Thus, it can be argued that non-access to employment is most often linked to variables specific to the socio-economic structure and characteristics of the individual, while access to an employment sector depends on the actions defined and implemented by the Government and on the other hand to the potential of the young person.

Our model therefore requires the use of several variables that we can group in the following way:

$>$ a Variable dependent on the equation of the first level or top level. It identifies the alternatives at this level, namely the two options available to young people who are looking for work: having access to a job or not;

$>$ a variable dependent on the second-level or bottom-level equation. An "employment-type" variable that identifies the different opportunities available to young people who have found a job ;

$>$ variables of access to employment or not (first level or top level). These variables are mainly related to the specific characteristics of the young person (age, education level, gender, social capital); institutional (favourable youth employment policies) and economic (economic) environment in the country;

$>$ explanatory variables of the choice of an employment sector (second level or bottom-level). These variables mainly relate to the individual characteristics of different employment sectors. Here we can remember the various public policies defined and implemented for young people (massive recruitment of young people to the civil service, the facilities granted to private companies that recruit young people, the technical and financial support provided to young people who wish to settle for themselves); the competent characteristics of young people (type of training, qualification area, entrepreneurial ability, professional experience, concern for stable situation). 


\section{Results and Interpretations}

Before presenting the results of the estimates of our interlocking multinomial logit model using the maximum likelihood method, we highlight the variables selected for this model our data from descriptive statistics.

\subsection{Descriptive Statistics of Our Variables}

Our variable dependent on the top level consists of two modalities: either the young person has access to employment or not (unemployment). Table 6, appendix, shows that the majority of our sample is unemployed (62.01\%) compared to only $37.91 \%$ of those who are employed. Table 7 in appendix shows our variable dependent on the second level. We find that the majority of young people who work are public sector employees (16\%), followed by private sector employees $(15 \%)$. We find that young people who move in on their own account account only $6.91 \%$. This situation can be explained by several factors including insufficient financial resources, the inability to set up a good project or the complexity of the procedures for setting up a business.

These dependent variables are explained by a set of independent variables whose average values and standard deviation (in parenthesis) are presented in the table below according to the level of equation on the one hand and the different employment sectors on the other.

Table 1. averages and standard deviations (in parentheses) of the variables in our analysis for different segments of the labour market

\begin{tabular}{|c|c|c|c|c|c|}
\hline \multirow[b]{2}{*}{ Variables } & \multicolumn{5}{|c|}{ Employment sectors } \\
\hline & Unemployed & $\begin{array}{l}\text { Public sector } \\
\text { employment }\end{array}$ & $\begin{array}{l}\text { Private sector } \\
\text { employment }\end{array}$ & $\begin{array}{c}\text { Self } \\
\text { employment }\end{array}$ & Together \\
\hline $\begin{array}{l}\text { General characteristics of the young } \\
\text { person, environment institutionnel et } \\
\text { économique du pays } \\
\text { environnement institutionnel et } \\
\text { économique du pays }\end{array}$ & & & & & \\
\hline Ages & $26,44(5,24)$ & $22,05(0,78)$ & $24,58(0,49)$ & $33,64(1,21)$ & $25,12(5,36)$ \\
\hline $\begin{array}{l}\text { Ages squared/100 } \\
\text { Sexes }(1=\text { male }) \\
\text { Marital status }(1=\text { married }) \\
\text { Highest diploma }(1=\text { GCE AL) } \\
\text { Social capital }(1=\text { yes }) \\
\text { Employment policy }(1=\text { yes }) \\
\text { Economic conditions }(1=\text { good })\end{array}$ & $\begin{array}{c}7,26(2,76) \\
1,45(0,49) \\
2,12(1,59) \\
2,32(1,63) \\
1,84(0,40) \\
0,3(0,08) \\
0,5(0,1)\end{array}$ & $\begin{array}{l}4,86(0,34) \\
1,55(0,49) \\
1,72(1,46) \\
2,68(1,54) \\
1,74(0,50) \\
2,00(0,56) \\
1,88(0,41)\end{array}$ & $\begin{array}{l}6,04(0,24) \\
1,55(0,50) \\
2,04(1,60) \\
2,77(1,83) \\
1,79(0,48) \\
1,97(0,68) \\
1,13(0,38)\end{array}$ & $\begin{array}{l}11,33(0,81) \\
1,48(0,48) \\
2,51(1,54) \\
2,66(1,94) \\
1,93(0,24) \\
1,95(0,80) \\
1,82(0,38)\end{array}$ & $\begin{array}{l}6,59(2,76) \\
1,52(0,49) \\
1,98(1,53) \\
2,57(1,68) \\
1,81(0,43) \\
1,97(0,59) \\
1,88(0,33)\end{array}$ \\
\hline $\begin{array}{l}\text { Specific skills, psychological status of the } \\
\text { young person and various public actions } \\
\text { in his favour }\end{array}$ & & & & & \\
\hline Type of training (1-professional) & $1,58(0,62)$ & $2,78(0,42)$ & $1,87(0,33)$ & $1,55(0,58)$ & $1,63(0,64)$ \\
\hline Qualification area (1-management) & $1,49(0,57)$ & $2,04(2,01)$ & $1,60(0,60)$ & $1,39(0,57)$ & $1,59(0,58)$ \\
\hline Entrepreneurial capacity (1-yes) & $1,07(0,41)$ & $2,14(3,02)$ & $1,62(0,58)$ & $2,48(0,56)$ & $2,68(0,49)$ \\
\hline Concern for stable situation (1-yes) & $1,12(0,69)$ & $1,98(0,41)$ & $2,67(0,49)$ & $1,51(1,45)$ & $1,73(1,73)$ \\
\hline $\begin{array}{l}\text { Work experience (1-yes) } \\
\text { Minimum income }\end{array}$ & $\begin{array}{c}1,18(0,63) \\
188840(17,19)\end{array}$ & $\begin{array}{c}1,48(0,58) \\
222475 \\
(1,02)\end{array}$ & $\begin{array}{c}2,04(1,93) \\
258563(3,20)\end{array}$ & $\begin{array}{c}1,51(0,34) \\
210545 \\
(0,35)\end{array}$ & $\begin{array}{c}1,76(0,42) \\
195241(1,73)\end{array}$ \\
\hline Investment structure (1-yes) & $1,89(0,88)$ & $1,11(0,65)$ & $1,67(0,58)$ & $1,18(0,40)$ & $1,21(0,41)$ \\
\hline Direct recruitment actions (1-yes) & $1,79(0,61)$ & $1,86(0,57)$ & $1,63(0,66)$ & $1,03(0,54)$ & $1,90(0,29)$ \\
\hline $\begin{array}{l}\text { Technical, financial and material support } \\
\text { (yes) }\end{array}$ & $1,92(0,87)$ & $1,21(0,67)$ & $1,21(0,42)$ & $1,87(0,23)$ & $1,98(0,13)$ \\
\hline Subsidies and tax exemptions (1-yes) & $1,62(0,48)$ & $1,25(0,12)$ & $1,97(0,31)$ & $1,21(0,23)$ & $1,70(0,45)$ \\
\hline Number of individuals (percentage of total) & $7122(0,62)$ & $1858(0,16)$ & $1770(0,15)$ & $721(0,07)$ & $11471(1)$ \\
\hline
\end{tabular}

Source: author calculations from EISS database, 2011 


\subsection{Results of our Estimates}

Tables 2 and 3 below give the results from the LME and LM models respectively. It should be noted at the outset that in these two tables, the coefficients are interpreted differently from those of a "usual" multinomial logistics model. In the latter, the coefficients are interpreted as the effect of a unit increase in the variable on the chances of making a particular choice rather than the "excluded" or "reference choice" choice for which the coefficients are arbitrarily kept at zero for technical reasons. Here, the factors on access to employment are interpreted as the marginal effect of a unitary variation of the variable considered on the non-employment (unemployment) rather than the obtaining of that job. The coefficients on access to an employment sector give the marginal effects of a unitary variation of the variable considered on access to an employment sector.

Knowing that the primary advantage of the LME model is to release, at least partially, the strong IIA hypothesis specific to the LM model, a Hausman-McFadden specification test of the IIA hypothesis was conducted on the LM model. The result of this test does not disprove the IIA hypothesis. The possible "superiority" of the LME model will therefore have to be measured in hindsight since the IIA hypothesis is not yet formally questioned. The I parameter in the LME model could be used to test the IIA hypothesis (see above, equation (2)); a test of hypothesis I-1 may indeed be an effective test of the relevance of the latter in the LM model (and therefore of the possible interest of using an LME model). This result is much more interesting. The parameter I has a significant different value of the unit $(2,124)$ and above all the zero hypothesis I - 1 is rejected at $1 \%$.It can be concluded that in this case, the LM model is not an appropriate tool for assessing the explanatory factors of access to employment. The results suggest that the proposed alternatives in the employment sectors are closer substitutes. For the sake of rigor other tests to verify the superiority of the LME over the LM can be performed.

Tables 2 and 3 below show that the results obtained from the LME model are interesting in that they provide a large number of significant variables, both in the explanation of access to employment and in the explanation of access to employment and in the analysis of access to different employment sectors. The chosen specification option, which is to assume that access to employment depends on the individual characteristics of the young person, institutional and cyclical factors, while the orientation towards an employment sector depends on the intrinsic skills of the young person and the integration mechanisms proposed by the government, seems to allow for a better explanation of the different situations. Indeed, variables such as age, gender, highest degree, social capital, institutional and cyclical head of household can be considered to influence obtaining employment, but not necessarily access to a particular sector of employment. On the other hand, the variables related to the young person's skills and the various offers of the State will rather play on his orientation towards a sector if he ever has the chances to get a job.

Table 2. Results of the Interlocking Multinomial Logistics Model (ML) Estimates of our Employment Equation

\begin{tabular}{|c|c|c|c|c|}
\hline \multirow[b]{2}{*}{ Variables } & \multicolumn{4}{|c|}{ Employment sectors } \\
\hline & $\begin{array}{c}\text { Unemplo } \\
\text { yed }\end{array}$ & $\begin{array}{l}\text { Public } \\
\text { sector } \\
\text { employm } \\
\text { ent }\end{array}$ & $\begin{array}{c}\text { Private } \\
\text { sector } \\
\text { employme } \\
\text { nt }\end{array}$ & $\begin{array}{c}\text { Self } \\
\text { employm } \\
\text { ent }\end{array}$ \\
\hline
\end{tabular}

General characteristics of the young person, the institutional and economic environment of the country

Ages

Ages squared / 100

$-0,36$

$(-0,02)^{* *}$

Sexes $(1=\operatorname{man})$

Highest diploma (1 = License)

Social capital (1-yes)

Employment policy (1=yes)

Economic Conjuncture (1=favorable)

$\begin{array}{cccc}0,24 & --- & -- & -- \\ (0,05)^{* * *} & & --- & -- \\ -0,89 & --- & - & -- \\ (-0,45)^{* *} & & & \\ 0,47 & --- & -- & -- \\ (0,02)^{* * *} & & & \\ -0,89 & --- & --- & -- \\ (-0,32)^{* *} & & -- & -- \\ -0,34 & --- & - & \\ (-0,06)^{* *} & & & \\ -0,52 & --- & -- & \\ (-0,08)^{*} & & & \end{array}$


Specific skills, psychological status of the young person and various public actions in his favour

Type of training (1=academic)

Qualification area (1=management)

$\begin{array}{cccc}--- & 0,78 & -0,46 & -0,03 \\ --- & -0,29 & 0,78 & 0,32 \\ & (-0,12)^{* *} & (0,42)^{* *} & (0,30)^{* *} \\ ---- & -0,28 & -0,32 & 0,72 \\ & (-0,10)^{* *} & (-0,11)^{* *} & (0,31)^{* * *} \\ --- & 0,58 & -0,47 & -0,35 \\ & (0,44)^{* * *} & (-0,26) & (-0,31)^{* *} \\ & 0,45(0,26) & 0,61 & 0,45 \\ -- & & (0,22) & (0,41) \\ & 0,59 & 0,82 & 0,47 \\ --- & (0,29)^{*} & (0,23) & (0,23) \\ & -0,28 & 0,34 & 0,29 \\ --- & (-0,41)^{* * *} & (0,22)^{* * *} & (0,12)^{* * *} \\ & 0,45 & -0,36 & -0,32 \\ --- & (0,26)^{* * *} & (-0,22)^{* *} & (-0,13)^{* *} \\ & -0,25 & -0,31 & 0,41 \\ --- & (-0,48)^{* *} & (-0,13)^{* *} & (0,21)^{* * *} \\ & -0,21 & 0,38 & 0,22 \\ & (-0,23)^{* *} & (0,33)^{* * *} & (0,18)^{* * *}\end{array}$

Inclusive value $\lambda$

2,124

$(1,12)^{* * * *}$

-2Log Likelihood = -645,148

$\mathrm{P}^{2}\left(\operatorname{sig} \mathrm{P}^{2}\right)^{1}=387,87(0,000)$

$\mathbf{R}^{2}$ adjusted $^{2}=0,401$

$=11471$

Source: author calculations from EISS database, 2011

Table 3. Results of the Multinomial Logistics Model (ML) estimates of our employment equation

\begin{tabular}{|c|c|c|c|c|}
\hline \multirow[b]{2}{*}{ Variables } & \multicolumn{4}{|c|}{ Secteurs de l'emploi } \\
\hline & Unemployed & $\begin{array}{l}\text { Public } \\
\text { sector } \\
\text { employmen }\end{array}$ & $\begin{array}{l}\text { Private sector } \\
\text { employment }\end{array}$ & $\begin{array}{c}\text { Self } \\
\text { employment }\end{array}$ \\
\hline
\end{tabular}

Caractéristiques générales du jeune,

environnement institutionnel et

économique du pays

Ages

Ages squared /100

Sexes $(1=\operatorname{man})$

Highest Diploma (1=Licence)

Social capital (1=yes)

Employmen policy (1=yes)

Economic conjuncture (1=favorable)

$\begin{array}{cccc}-0,31(-0,04)^{* *} & --- & --- & --- \\ 0,29(0,09)^{*} & --- & --- & --- \\ -0,88(-0,48)^{*} & --- & -- & -- \\ 0,35(0,01)^{*} & --- & --- & -- \\ -0,84(-0,40) & --- & -- & --- \\ -0,3(-0,08)^{*} & --- & -- & --- \\ -0,5(-0,1) & --- & -- & --\end{array}$




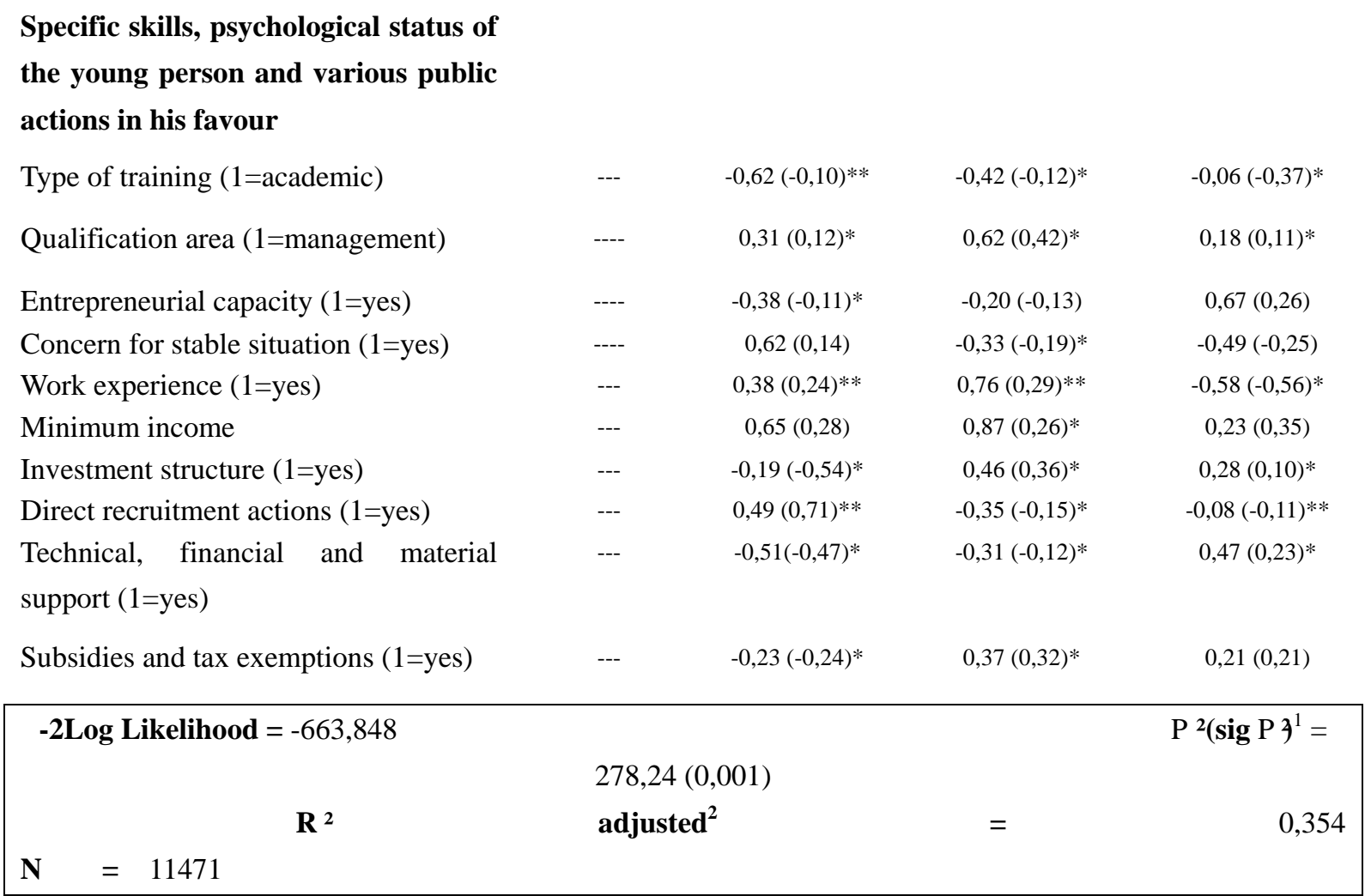

Source: author calculations from EISS database, 2011

Notes for Tables 2 and 3: the values in parentheses represent the student's $\mathrm{t}$; $* * *=$ significant at $1 \%$, ** $=$ significant at $5 \%, *=$ significant at $10 \%$; (1) test of the likelihood ratio calculated according to RV = 2 (L1-L0) where L1 corresponds to the -2 Log Likelihood of the unconstrained model and L0 corresponds to the -2 Log Likelihood of the constrained model; it follows a chi² law at $\mathrm{N}-(2 \mathrm{k}-1)$ degrees of freedom, $\mathrm{k}$ being the number of variables; (2) this is an adjusted pseudo-R ${ }^{2}$ equal to: 1 - (L1 / L0)

The age of individuals increases the chances of participation in the labour market in a very significant way. The negative sign means that increasing age decreases the chances of getting a job. This is all the more true for the Cameroonian case, especially in the recruitment of the public service, since the age limit for participation in a competition is 32 years. The quadratic aspect of the age-access to employment relationship is demonstrated by the negative sign and the strong significance of the age-related coefficient divided by one hundred. The coefficient of "sex" of individuals shows that being a man, all other things being equal, increases the chances of getting a job. The variable "highest degree" has a positive and significant sign at $1 \%$. This means that a highly educated young person is more likely not to get a job. This is due to the fact that most employers in Cameroon who are looking at reducing costs prefer to recruit young people who do not have enough degrees since the remuneration will also be lower. The coefficient of the variable "social capital" is negative and significant at $5 \%$. This result reflects the reality of Cameroon since obtaining a job is very often conditioned by the existence of a strong relationship network that supports the young person's candidacy. The variable "employment policy" has a negative and significant sign at 5\%. This means that the young person who benefits from the government's facilitating measures does not find himself unemployed. Also, when the economic situation is favourable, the obtaining of employment is guaranteed if we take note of this coefficient.

With regard to access to one sector of employment, we observe that young people who have received academic training are more likely to work in the public sector, their chances in other sectors are negative; the significance of these coefficients ranges from $1 \%$ to $5 \%$. Also, the fact that a young person has a management qualification significantly increases his chances of being in the private sector by simultaneously reducing his chances of being employed to the public. Having entrepreneurial skills greatly increases the chances of self-employment, at the expense of the chances of accessing the other two segments. Young people who are concerned about stable employment significantly increase their chances of ending up in the public sector at the expense of the other two 
sectors. Young people with work experience are more likely to work in the private sector than in the other two sectors. The values of these coefficients and their level of significance tell us about the effects of individual skills on access to any other sector of employment in Cameroon.

We are currently analysing the effects of public policies on youth employment. Young people who benefit from the support of investment structures (such as the NEF, BMO, etc.) increase their chances of accessing the private sector more than to self-employment and decrease the chances of access to the public sector. Young people who benefit from direct recruitment measures significantly increase their chances of accessing the public sector, particularly in the public sector, at the expense of the private sector and self-employment. Also, young people who receive technical, material and financial support from structures such as ISPAIS, RUYSP, etc. significantly increase their chances of self-employment and decrease their chances of being employed in the public and private sector.

Finally, tax exemptions and government subsidies increase the young person's chances of accessing the private sector rather than self-employing and reduce the young person's chances of being employed in the public sector. These results show us that the various public policies defined and implemented by the Cameroonian government are bearing fruit. But the low value of these coefficients indicates that these measures are not effective.

Comparison of marginal effects from the two estimated models, allows for a more direct comparison of the results of the LME and LM models. It appears that there are significant discrepancies between the two estimates. The marginal effects on access to employment do not show the notable differences for the two models. The differences are more or less pronounced when one considers the marginal effects of public policies on the choice of an employment sector. The role of direct recruitment action, for example, is more pronounced on the LME than on the LM. This succinct comparison of the marginal effects estimated by our two models, which reveals a number of significant discrepancies, is in the direction of a more careful consideration of the possibility of implementation of models releasing the IIA hypothesis.

Table 4. Marginal Effects in LME and LM Models

\begin{tabular}{|c|c|c|c|c|c|c|c|}
\hline \multirow{3}{*}{ Variables } & \multicolumn{7}{|c|}{ Employment sectors } \\
\hline & Une & & $\begin{array}{l}\text { Public sector } \\
\text { employment }\end{array}$ & $\begin{array}{l}\text { Priv } \\
\text { emp }\end{array}$ & & Self e & ment \\
\hline & LME & LM & $\begin{array}{l}\text { LME } \\
\text { LM }\end{array}$ & LME & LM & LME & LM \\
\hline
\end{tabular}

General characteristics of the young person,

the institutional and economic environment

of the country

Ages

$-1,48$

$-0,23$

Ages squared /100

$+0,89 \quad+1,9$

Sexes $(1=\operatorname{man})$

$-2,83$

$-1,48$

Marital status $(1=$ married $)$

Highest diploma (1=BAC)

$$
\begin{gathered}
-0,05{ } \quad 0,01 \\
+0,38 \\
+0,23
\end{gathered}
$$

Social capital (1=yes)

$-2,12$

$-1,28$

Employmen policy (1=yes)

$-0,47$

$-0,16$

Economic conjunture (1=favorable)

$-1,52$

$-0,58$ 


$\begin{aligned} & \text { Specific skills and psychological state of the } \\ & \text { young person, different public actions on }\end{aligned}$
behalf of young people
Type of training (1-professional)

Italic values correspond to non-significant variables in the models concerned; they are therefore reproduced only as an indication and cannot give rise to any interpretation.

Source : calculs auteurs à partir de la base EISS, 2011

\section{Conclusion}

The aim of this article was to assess the effects of public policies on youth employment in Cameroon. To do this, we first conducted a literature review which allowed us to see that state interventions are a group of passive and active policies. The latter focus first on measures relating to education policy because the idea is that youth unemployment is due to a problem of inadequate or inadequate training. Second, governments can intervene directly in the labour market through mass recruitment. Finally, incentives (tax exemptions, various subsidies) to private partners to encourage the recruitment of young people. To evaluate these public policies in Cameroon, we used the interlocking multinomial logit model, which not only corrects the limitations of the multinomial logit model, including IIA ownership, but also considers multi-level alternatives. The chosen estimation technique is the maximum likelihood.

After conducting the Hausman-McFadden specification test of the IIA hypothesis on the LM model, the result of this test did not allow us to disprove the IIA hypothesis. We found the result satisfactory by testing the parameter I which did have a significant different value of the unit $(2,124)$ and especially the zero hypothesis I-1 which was rejected at $1 \%$. This justifies the use of the LME. Our estimates show that the various public policies defined and implemented by the Cameroonian Government allow young people to be integrated into different sectors, but not substantially. Many young people are still looking for a job because they have not had the chance to join the civil service despite the massive recruitments carried out by the State, they are unable to benefit from recruitment in private companies or to settle on their own account. Faced with this situation, the Cameroonian State should further strengthen the professionalisation of training and, above all, direct training offers in areas that present opportunities in our country, including agriculture, computer engineering and agri-food. Similarly, the government needs to strengthen the facilities granted to private enterprises to encourage them to recruit more young people, it must improve the business climate that is conducive to the growth of these enterprises, which 
will eventually enable the recruitment of young people. It should also increase investment in ICT infrastructure to enhance the opportunities offered by their use. Finally, we suggest that the Government of Cameroon provide more technical and material support to young people who are seeking it and, on the other hand, to mobilise more funds for the financing of bankable projects presented by these young people.

Note In Cameroon's policy of vocational integration of young people, the State considers anyone between the ages of 17 and 35. However, from the point of view of the World Bank and other entities such as the European Union, it is the age group [15-25] that is chosen.

${ }^{1}$ Under employment

${ }^{1}$ Products derived from innovation and technological change, for example

1 The first applications were then mainly carried out in the field of biology, sociology and psychology

1 The Anglo-Saxon term is "independence of irrelevant alternatives" (IIA). It is sometimes presented more explicitly as the "red-bus/blue-bus problem": in a three-choice model of transport, it implies that the relative probabilities between the choice of car or red bus are always specified in the same way, whether the third possible choice is a blue bus or the train. This property also means that the percentages (predicted by the model) of individuals choosing each of the alternatives will decrease in proportion to their initial importance if an additional choice is introduced into the model (regardless of that choice).

1 Three tests of the IIA hypothesis, based respectively on the use of a Lagrange multiplier, a likelihood test or a Wald statistic, were proposed by McFadden (1987).

${ }^{1}$ As McFadden (1984) and Amemiya (1985) and Greene (1997) point out. Although the model is now computable, it still poses quite a lot of difficulties in interpreting the coefficients.

1 The first to present this model was Ben-Akiva (1973).

${ }^{1}$ The situation we are defining here is obvious. However, when this is not the case, it is possible to store the alternatives in subgroups. Thus, when the IIA hypothesis holds (or is respected) between two alternatives, they can be stored in the same subset or subgroup.

${ }^{1}$ In a way, the coefficient is a measure of the "independence" of the choices of the subgroup consisting of the three opportunities in the employment sectors compared to the previous possibility, that of non-access to employment

1 The latter, two of them, were also proposed by McFadden (1984). This is a test based on the statistic of the Lagrange multiplier and another implementing a test of the probability ratio.

\section{References}

Amemiya, T. (1985). Advanced econometrics. Cambridge: Harvard University Press 1985.

Andrea, B., \& Romain, D. (2009). Unemployment, institutions and reform complementarities: Re-assessing the aggregate evidence for OECD countries. Post-Print halshs-00395144, HAL

BAfD. (2016). Stratégie du Groupe de la Banque pour l'emploi des jeunes en Afrique 2016-2025. Annual Meetings in May 2016 in Lusaka, Zambia.

Card, D. K., \&Alan, B, (1997). Minimum Wages and Employment: A Case Study of the Fast-Food Industry in New Jersey and Pennsylvania. American Economic Review, American Economic Association, 84(4), 772-793.

Crépon, B., Marc, F., \& Denis, F. (2012). Training the Unemployed in France: How Does it Affect Unemployment Duration and Recurrence? Published in 2012. https://doi.org/10.2307/23646576

EISS. (2011). Employment and Informal Sector Survey. Yaounde 2011.

Richard, K. G., \& Patrick, H. H. (2001). Home-ownership and Unemployment in the US. Urban Studies, 38(9), 1509-1520. https://doi.org/10.1080/00420980126669

Hanushek, E. A., \& Woessmann, L. (2012). Do better schools lead to more growth? Cognitive skills, economic outcomes, and causation. https://doi.org/10.1007/s10887-012-9081-x

Hausman, J., \& Mc Fadden, D. (1984). A specification test for the multinomial logit model. Econometrica, 52, 1219-40. https://doi.org/10.2307/1910997

Heckman, J. (1976). The Common Structure of Statistical Models of Truncation, Sample Selection and Limited Dependent Variables and a Simple Estimator for Such Models. Annals of Economic and Social 
Measurement, 5, 475-492.

Laroque, G., \& Salanié, B. (1999). Prélèvements et transferts sociaux : une analyse descriptive des incitations financières au travail. Économie et Statistique, 328, 3-20. https://doi.org/10.3406/estat.1999.6341

Lee M. C., Karen L. J., Robin, P. N., \& Joan, I. W. (2013). Evidence-based practice process quality assessment: EPQA guidelines. Worldviews Evid Based Nurs2013 Aug; 10(3), 140-149. https://doi.org/10.1111/j.1741-6787.2012.00264.x

McFadden, D. (1973). Conditional Logit Analysis of Qualitative Choice Behavior. In P. Zarembka, ed., Frontiers in Econometrics, New York: Academic Press 1973.

McFadden, D. (1974). Conditional Logit Analysis of Qualitative Choice Behaviour. In P. Zarembka, Ed., Frontiers in Econometrics, Academic Press, New York, 1(2), 105-142.

McFadden, D. (1984). Econometric Analysis of Qualitative Response Model. Handbook of Econometrics. vol. II, Z. Griliches et M. D. intriligator (eds), Elsevier Science Publishers 1984. https://doi.org/10.1016/S1573-4412(84)02016-X

McFadden, D. (1987). Regression Based Specification Tests For The Multinomial Logit Model. Journal of Econometrics, 34, 63-82. https://doi.org/10.1016/0304-4076(87)90067-4

Nickell, S. (1998). Unemployment: Questions and Some Answers. https://doi.org/10.1111/1468-0297.00316

Nickell, S. (1997). Unemployment and Labor Market Rigidities: Europe versus North America. Journal of Economic Perspectives, 11(3), 55-74. https://doi.org/10.1257/jep.11.3.55

Nicoletti, \& Scarpetta (2005). Product Market Reforms And Employment in OECD Countries. ECO/WKP(2005)59.

Nunziata, \& Luca (2002). Unemployment, Labour Market Institutions and Shocks. Economics Papers 2002-W16, Economics Group, Nuffield College, University of Oxford.

Ryan, P. (2001). The School-to-Work Transition: A Cross-National Perspective. Journal of Economic Literature, 39(1), 34-92. https://doi.org/10.1257/jel.39.1.34

Sabina, I. (2016). Les politiques publiques d'insertion professionnelle des jeunes : la France peut elle s'inspirer des expériences étrangères? Revue Interventions économiques. Retrieved from http://www.semanticscholar.org

Salanié, B. (1999). The Economics of Contracts. Cambridge, MA: The MIT Press.

Scarpetta \& Elmeskov (1998). Find a positive effect in some of their estimated equations, 1998.

Scarpetta, (1996). Find a positive effect in some of their estimated equations, 1996.

World Bank. (2012). Dynamiser le marché du travail Point sur la situation économique du Cameroun : spécial Emploi. Cahier économique du Cameroun 2012.

\section{Appendix}

Annexes

Table 5. Respondents' Region of Residence

\begin{tabular}{llll}
\hline & Workforce & Percentages & Cumulative percentages \\
\hline Douala & 2007 & 15.31 & 15.31 \\
Yaoundé & 1778 & 13.57 & 28.87 \\
Adamaoua & 843 & 6.43 & 35.31 \\
Center & 998 & 7.61 & 42.92 \\
East & 866 & 6.61 & 49.53 \\
Far north & 1453 & 11.08 & 60.61 \\
Littoral & 791 & 6.03 & 66.64 \\
North & 965 & 7.36 & 74.00 \\
North west & 874 & 6.67 & 80.67 \\
West & 1088 & 8.30 & 88.97 \\
South & 721 & 5.50 & 94.47 \\
South west & 725 & 5.53 & 100.00 \\
Total & 13110 & 100.00 & \\
\hline Source: & & & \\
\hline
\end{tabular}

Source: author calculations from EISS database, 2011 
Table 6. Do you have a job?

\begin{tabular}{llll}
\hline & Workforce & percentages & Cumulative percentages \\
\hline Yes & 4349 & 37.91 & 37.91 \\
No & 7122 & 62.09 & 100.00 \\
Total & 11471 & 100.00 & \\
\hline
\end{tabular}

Source: author calculations from EISS database, 2011.

Table 7. Types of Employment

\begin{tabular}{lccc}
\hline & Workforce & Percentages & Cumulative percentages \\
\hline Public sector employees & 1858 & 16,00 & 16,00 \\
Private sector employees & 1770 & 15,00 & 31,00 \\
Self-employment & 721 & 6,91 & 37,91 \\
Unemployed & 7122 & 62,09 & 100,00 \\
Total & 11471 & 100,000 & \\
\hline
\end{tabular}

Source: author calculations from EISS database, 2011.

\section{Copyrights}

Copyright for this article is retained by the author(s), with first publication rights granted to the journal.

This is an open-access article distributed under the terms and conditions of the Creative Commons Attribution license (http://creativecommons.org/licenses/by/4.0/). 